\title{
Capítulo 12
}

\section{Visitas y formas de corrección entre los dominicos del Nuevo Reino de Granada}

Andrés Mauricio Escobar Herrera"

$\mathrm{E}$ 1 siglo XVIII ha sido caracterizado como la era del regalismo. Entendido como "la manifestación de los anhelos de la Monarquía moderna de ejercer la autoridad regia en todos los terrenos sin menoscabo alguno" (Cortés, 1989, p. 15), en España el reinado de Carlos III (1759-1788) es considerado como el prototipo de gobierno fundado en esta doctrina. La implementación de un modelo de Estado "absoluto y absorbente, cuya esencia misma es la inflación de poder y cuya dinámica final consiste en la total incorporación a su órbita de todas las esferas de la acción del hombre" (José Cepeda Adán, El siglo crítico y fenoménico citado en Cortés, 1989, p. 15), debía partir de la conciliación o la dominación de los amplios poderes eclesiásticos, pues la Iglesia contaba por sus propios estatutos con franjas de libre actuación que sustraían su labor espiritual, disciplinaria y económica del control directo del poder político.

La intervención regalista en asuntos eclesiásticos asumió diversos matices: desde los intentos de vigilar al clero secular dado su incontestable "control de amplios sectores de la población a través de la educación y la

* Docente investigador del Instituto de Estudios Socio-Históricos Fray Alonso de Zamora -Ieshfaz— de la Universidad Santo Tomás (Sede Bogotá). 
cura de almas, [la] función de benefactor para los pobres y [el] incuestionable dominio en el terreno religioso" (Cortés,1989, p. 15); hasta las cortapisas a la influencia de Roma, considerada por algunos de los ilustrados como una potencia extranjera que limitaba la acción centralizadora del Estado. ${ }^{1}$ En el caso de los reinos indianos, el poder del clero era quizá más notorio, sobre todo si se tiene en cuenta que el número de eclesiásticos y religiosos era mucho menor que en España. Como le refiriera el intendente del Cuzco Benito Mata Linares al ministro de Indias José de Gálvez en 1783, "esta América es enteramente eclesiástica, y en ella más imperio tiene un cura que todo el brazo del Rey” (Domínguez, 1986, p. 34).

Quizá el principal capítulo de la reforma "carolina” del clero fue el concerniente a las órdenes religiosas. Percibidas como dependientes del papa y no de la Corona, para los ilustrados más verticales las comunidades regulares eran "Estados dentro del Estado", ejércitos extraños cuya fidelidad estaba en Roma y no en España. "Los frailes no tienen patria” reza la lapidaria sentencia del consejero de Carlos III Jerónimo Grimaldi: "Desde el momento en que profesan se deben mirar como extranjeros. Es una milicia en la que los papas han hallado el secreto de mantener a costa de los mismos pueblos a quienes hacen la guerra. $\mathrm{Ni}$ son españoles, napolitanos ni franceses; son romanos donde quiera que se hallen" (Barrio, 2000, p. 90).

La fuerte descalificación de los religiosos se debía a varios factores: primero, a su carácter evidentemente trasnacional, situación que los monarcas quisieron contener privilegiando en los nombramientos

1 Es innegable, entonces, que para varios de los ministros y consejeros de los monarcas españoles la religión se perfiló como instrumento político. "Esta tendencia apuntó a reordenar la organización y el poder eclesiástico bajo la autoridad regia, con objeto de que esta fuera reforzada con la autoridad espiritual y la fuerza temporal de la Iglesia" (Martí, 2004, p. 49). Así, la institución eclesiástica se convirtió en blanco de miradas y críticas de todo orden, a pesar de que, como dice Sarrailh, "la masa de la nación [siguió] confiada enteramente en sus sacerdotes y en sus frailes, indiferente a ese combate", entregada a "sus preocupaciones diarias, mucho más humildes y dolorosas", en medio de las cuales "la tradición [y] las ceremonias piadosas [eran] uno de [los] pasatiempos preferidos, fuente de emociones y de esperanzas del más allá" (Sarrailh, 1957, p. 612). En otras palabras, el regalismo en materia eclesiástica nunca significó menoscabo de la religiosidad. 
y pases a los frailes españoles; segundo, a la independencia con que fueron instituidos frente a las autoridades diocesanas; y tercero, particularmente en España, a su elevado número. Así, en un momento en el que las estructuras del gobierno hacían lo posible por introducir reformas de orden económico para aprovechar los recursos, las comunidades religiosas fueron percibidas como refugio de los "ociosos" y un "peso inútil” para el Estado. Interrogado por su repulsión hacia los jesuitas, el ministro Pedro Rodríguez de Campomanes respondió "que los odiaba como a todas las órdenes religiosas, raza parásita y dañosa, y que, si solo dependiera de él, las haría desaparecer a todas de la Península y del mundo entero" (Memories de Jacques Casanova de Seingalt en Sarrailh, 1957, 647). ${ }^{2}$

\section{La reforma de los regulares en el Nuevo Reino}

La reforma del clero regular se hizo extensiva a Indias y las Filipinas, territorios para los cuales el rey Carlos III estipuló una real instrucción particular ${ }^{3}$. En esta ordenó a cada una de las órdenes religiosas designar cuanto antes tres visitadores envestidos con las facultades de reformadores, quienes, una vez aprobados por el Monarca en razón de su "virtud, desinterés, letras y experiencia”, debían pasar “a aquellos dominios, con el saludable fin de restablecer en tan dilatadas

2 Justamente, la expulsión de la Compañía de Jesús fue el acto más representativo de las pretensiones regalistas de la Corona española, un "golpe de timón" que dejó en claro el predominio de las regalías y el papel del gobierno como "protector de la Iglesia y celador de su disciplina” (Sánchez-Blanco, 2002, p. 74). Sus estrechas relaciones con Inglaterra, acérrimo rival de España, y su inclinación por el probalismo en desmedro del absolutismo sobre el que afincaban su poder todas las monarquías, representaron a los jesuitas como "el principal y único fomento que atizaba el fuego en todas partes, indisponía los ánimos de cualquier clase de gentes, los separaban del amor y subordinación al gobierno, imprimían y esparcían papeles y escritos sediciosos contrarios a la autoridad real y a la soberanía y sus legítimos derechos" (Martí, 2004, p. 125).

3 Se trata de la Real Instrucción sobre restablecer la disciplina monástica. San Lorenzo del Escorial, 16 de octubre de 1769. 
provincias la disciplina regular y monástica en su observancia" (Carlos III, 1769/1850, p. 167).

Al igual que en la Península, la visita practicada a las órdenes religiosas de América buscaba por la vía de la corrección disciplinaria tratar de introducirlas en el regalismo y mermar su independencia e influencia social. Los gobernantes neogranadinos no eran desde luego ajenos a esta tendencia. Por ejemplo, el virrey Pedro Messía de la Zerda, al hacer dejación del cargo en 1772, si bien advertía que hasta ese momento no se habían efectuado las visitas de los conventos por la falta de los reformadores y secretarios necesarios, celebraba las instrucciones reales al respecto, "por notarse en los regulares no pequeña infracción y desvío de la observancia de sus respectivas reglas, con un engreimiento fundado en la independencia y exenciones con que se estiman privilegiados" ("Relación del estado del Virreinato", 1772/1989, p. 127).

En ese mismo año, en su informe sobre el "estado del Virreinato de Santafé”, el fiscal Francisco Antonio Moreno y Escandón prefirió omitir "toda narración en orden a costumbres y observancia de los estatutos regulares, como asunto no solo delicado sino también reservado al juicio de la reforma mandada practicar" ("Estado del Virreinato de Santafé", 1772/1989, p. 265). De todas maneras, el despacho de Moreno proporciona un dato sobre la singularidad de la reforma de los regulares americanos con respecto a la de los españoles. Según dicha memoria, en el Virreinato se contaban 76 conventos y casas de órdenes masculinas, las cuales albergaban a una población de 843 regulares entre sacerdotes y legos. ${ }^{4}$ Guardadas las proporciones entre ambos territorios, estas cifras contrastan notablemente con las registradas en España, en dónde según los censos de población para 1752 existían 63.303 frailes (Barrio, 2000,

4 Los más numerosos eran los franciscanos con 25 conventos que albergaban a 256 religiosos; les seguían los dominicos con 16 y 223 respectivamente, los agustinos calzados con 15 conventos para 176 religiosos, los agustinos descalzos que tenían 100 regulares repartidos en 6 conventos, y finalmente, los hospitalarios de San Juan de Dios con 14 casas o conventos-hospitales con 88 frailes (véase "Estado del Virreinato de Santafé”, 1772/1989, p. 265). 
p. 91). Así, mientras los reformadores tenían la premisa de reducir el excesivo número de religiosos en la Península para contrarrestar la "holgazanería” y demás "vicios" propiciados por esta circunstancia, en el Nuevo Reino dicha justificación perdía fundamento, pues “en comparación a su bajo número los frutos producidos eran notables, de modo que no se les podía acusar de buenos para nada" (Plata, 2012, p. 193).

De este modo, para 1776, sin que aún se ejecutaran en su totalidad las visitas regias estipuladas siete años atrás, el virrey Manuel Guirior señaló en su Relación de mando que urgía una reforma general del clero regular del Nuevo Reino, dados "los muchos desórdenes dimanados de la libertad con que suelen vagar fuera de sus conventos, sin sujeción, formándose privados peculios y valiéndose para ello de todos los medios que presenta la ambición" "Instrucción que deja a su sucesor", 1776/1989, p. 281). Aunque la política eclesiástica de Carlos III —como ya se dijo- también contemplaba ajustes del clero secular, a juicio de Guirior esta apremiaba tanto o más entre los religiosos, "por el respeto con que son atendidos por el común de los pueblos, a quienes deben sugerir máximas de cristiandad, sumisión y obediencia a los superiores", situación que —concluye el virrey— "me persuado no se verifique ínterin no se les reduzca a vivir de comunidad en sus conventos" ("Instrucción que deja a su sucesor”, 1776/1989, p. 282).

\section{Visitas y formas de corrección entre los dominicos}

Las visitas canónicas han sido una praxis de gobierno en la Iglesia católica que se remonta a sus primeros siglos. ${ }^{5}$ Estas permiten comprobar en las parroquias de cada diócesis desde el estado de los bienes (inmuebles, muebles y objetos litúrgicos) hasta la conducta e idoneidad de los clérigos, incluso la religiosidad de los feligreses. Como "acción inspectora" de obligatorio cumplimiento para los obispos solo

5 Existen referencias a visitas en concilios como los de Tarragona en 516 o Braga en 572 , en los cuales ya se nombran como "una antigua tradición" (véase, Arranz, 2003, pp. 301-302). 
fue establecida hasta el Concilio de Trento, junta que también ordenó en el capítulo XX de la sesión XXV, "que los superiores de las religiones [visitaran] y [corrigieran] los monasterios que les [estaban] sujetos [conforme a las constituciones de cada religión]" (López, 1787, sesión XXV, capítulo. XX, p. 379).

En la Orden de Predicadores las visitas canónicas formaban parte de las funciones del maestro general, quién en tanto "sucesor de Santo Domingo [fungía] como el prelado de todos los frailes, conventos y provincias dominicanas, con la legitimación que le otorgaba la profesión de obediencia"6 (Serrano, 2014, p. 64). La visita tenía como finalidad "comprobar que se cumplían las directrices acordadas en los capítulos generales y provinciales, es decir, recomendaciones relacionadas con la economía, la evangelización, las observancias o la administración conventual" (Serrano, 2014, p. 64). Los visitadores tenían facultad para corregir todas aquellas anomalías detectadas en la visita, periodo en el cual cesaba transitoriamente la autoridad de los priores conventuales.

Desde mediados del siglo XIII, el maestro Humberto de Romanis facultó a los provinciales para realizar vistas canónicas en los conventos y casas de sus jurisdicciones, las cuales solamente se establecieron como obligatorias en los cuatro años de cada provincialato en las constituciones editadas en 1689. El objetivo de las visitas entre los dominicos "estaba relacionado principalmente con el estado del personal en cuanto al cumplimiento de sus deberes, y detección y consiguiente corrección de eventuales irregularidades, abusos, errores, escándalos o desórdenes" (Esponera, 2013, p. 317). Los visitadores debían abstenerse de recibir dádivas de los conventuales visitados, así como poner especial cuidado en "que se observase lo mandado por la

6 Por la obediencia — decía el maestro Humberto de Romanis-: "Dios se enseñorea perfectamente del hombre, por esta es muy glorificado, pues por la obediencia del todo deja su propia voluntad, pues es sujeción, por la cual el hombre por amor de Dios voluntariamente se somete a la voluntad de otro hombre. [...] Por la obediencia se gana el más noble género de triunfo es, el vencerse así mismo: lo cual hace el obediente. Dice San Gregorio: cuando humildemente nos sujetamos a lo que otro manda, a nosotros mismos vencemos en el corazón” (Romanis, 1546, s.p.). 
Regla, Constituciones, actas de los últimos Capítulos Generales y Provinciales" (Esponera, 2013, p. 317). Como resultado de su inspección y valoración, el visitador levantaba un acta en la cual dejaba consignadas todas aquellas advertencias y disposiciones a su juicio necesarios para mantener o mejorar la observancia, las cuales debían permanecer vigentes hasta la siguiente visita. ${ }^{7}$

Además de los visitadores, el otro referente para corregir los yerros y mantener la vida regular eran los priores o prelados, quienes según las constituciones tenían amplias facultades para sancionar o absolver a los frailes por sus faltas. En orden a su trascendencia, los dominicos contemplaban cuatro tipos de culpas. Las "leves", entre las que se encontraban, entre otras, hacer ruido en la iglesia o las celdas, dormirse en las lecciones, cantar o rezar a destiempo de sus hermanos, llegar tarde a los actos de la comunidad, "reírse disolutamente y provocar [en] los demás con dichos o acciones, semejantes risadas"; "tratar con desaliño [la] ropa, [los] libros o los ornamentos"; perder o quebrar algo de la vajilla, comer o beber sin bendición, responder "con algún agrio o aspereza", y ser "negligente en su oficio y obediencia" (Regla de Nuestro Padre San Agustín, 1787, p. 51). Ante estas “culpas”, el prelado podía disponer discrecionalmente alguna penitencia, como venias, oraciones o ayunos.

Las culpas "graves" contemplaban conductas como murmurar de la comida, mentir, decir oprobios y formar pleitos a sus compañeros (peor aún si se hacia delante de seglares), ir a caballo, llevar dinero, comer carne sin licencia, romper el ayuno, "fixar la vista en alguna mujer o hablar solo con ella y no de confesión o cosas decentes" (Regla de Nuestro Padre San Agustín, 1787, p. 52). Si el culpable admitía la falta, la pena residía en "tres disciplinas y tres ayunos a pan y agua"; si era otro el que lo inculpaba, los mismos castigos subían a cuatro,

7 En la Orden de Predicadores también estaba contemplada la figura de los "visitadores delegados" nombrados por el maestro de la Orden o por un provincial, que debían ser: "frailes antiguos en la Orden, graves y maduros, ejemplares en sus costumbres y vida; no podían ser Priores, o Lectores en ejercicio, ni Provinciales fuera de su propia Provincia. Sus poderes debían estar señalados en las cartas patentes de su institución” (Esponera, 2013, p. 317). 
aunque si el delator no podía demostrar y "flaqueaba la prueba", pagaba la pena del talión.

Entre las culpas "más graves" estaban "ser rebelde al Prelado, conspirar contra él, amotinarle los frailes, poner en él manos violentas, solicitar salir de su obediencia o sacar a otro" (Regla de Nuestro Padre San Agustín, 1787, pp. 53-54). También falsificar los sellos del general, robar, jugar a los dados, tener armas ofensivas, dar veneno, dar falso testimonio e infamar a la Orden o algún particular. Asimismo, el homicidio, el pecado nefando, la embriaguez asidua y la herejía. Las culpas "más graves" daban lugar a penas "privativas", por ejemplo, quitándole al infractor los grados y cargos, la comunión y la facultad de predicar y oficiar los sacramentos. También se aplicaban penas "positivas" como la cárcel, las disciplinas, el "secuestro de los demás, sin que nadie le comunique ni le encargue nada"; "comer en tierra sobre el desnudo suelo pan basto y agua"; y "postraciones a la puerta del Coro, cuando entra y sale la Comunidad" (Regla de Nuestro Padre San Agustín, 1787, pp. 54-55). Cada prior podía absolver de estas penitencias a los reos en el tiempo que estimara prudente, menos al que difamara a la Orden, caso reservado al maestro general. Para los envenenadores, homicidas y sodomitas la pena era la cárcel por no menos de veinte años, y perpetua para el que abjurara (Regla de Nuestro Padre San Agustín, 1787, p. 55).

Finalmente estaban las culpas "gravísimas" en las que incurrían los escandalosos e incorregibles, aquellos reincidentes que además rehusaban las penas, así como los que murmuraran del papa, los mercaderes y los alquimistas. A estos los priores los podían encarcelar y mortificar con ayunos y abstinencias, y los maestros generales quitarles el hábito y expelerlos de la Orden. A los apostatas se les aplicaba la excomunión, y si por alguna razón regresaban, se debían presentar ante el Capítulo con la espalda descubierta para recibir "disciplinas" una vez a la semana por el tiempo que dispusiera el prelado (Regla de Nuestro Padre San Agustín, 1787, pp. 56-57). 


\section{Una visita general el convento San Sebastián Mártir de Popayán}

Tras una visita general, además de las actas particulares que se guardaban en cada convento, el provincial podía compendiar en una epístola una serie de recomendaciones para todos los religiosos de su jurisdicción, con las cuales buscaba principalmente homogeneizar la vida regular. Luego de la visita de 1693, el provincial Bartolomé García dispuso un amplio pliego para que todos los conventillos y conventos de la provincia de Santa Catalina de Quito guardaran los mismos tiempos y procedimientos en los servicios religiosos, en los estudios y en la administración conventual. Entre otros asuntos, se reglamentó el horario de las misas y oraciones, ${ }^{8}$ el rezo del rosario, ${ }^{9}$ la asistencia al coro, ${ }^{10}$ la

8 La misa conventual, que debía decirse todos los días del año, se oficiaba "a la nueve del día”, a menos que hubiera "alguna función foránea”, cuando se daba "a las ocho presidiendo siempre primero y segundo signo a las campanas". Con tañido se llamaba también a "las horas canónicas diurnas y nocturnas", diciéndose "las completas siempre entre las cinco o las seis de la tarde, y los maitines y laudes a las diez de la noche", excepto en los dos conventos de la ciudad de Quito, donde se rezaban "al punto de la medianoche” (Epístola dirigida a toda la Provincia, 1693, f. 2v).

9 El rosario debía rezarse en el coro de la iglesia y estaban obligados a asistir todos los conventuales sin excepción de dignidad o cargo.

10 Según lo mandado por diversos capítulos generales, los únicos excusados para faltar al coro eran el maestro general de la Orden y los padres provinciales. Sin embargo, al parecer se había extendido la práctica de que los priores conventuales faltaran a estos oficios, por lo que se deja expreso el aviso de que aquellos "negligentes" en la asistencia al coro, aunque priores, fueran privados "de sus oficios irremisiblemente” (Epístola dirigida a toda la Provincia, 1693, f. 3). 


\author{
práctica de la confesión, ${ }^{11}$ el cuidado de los ornamentos ${ }^{12}$ y las proce- \\ siones y oficios de difuntos. ${ }^{13}$
}

11 El sacramento de la confesión o penitencia de los fieles estaba mandado en las Constituciones. Los frailes confesores debían "salir a la iglesia a confesar los fieles que tuvieren devoción" de hacerlo en los templos dominicanos (Epístola dirigida a toda la Provincia, 1693, f. 3v). El provincial García también ordenó "que todas las veces que los curas fueren llamados a confesar a cualquier hora del día o de la noche o a sacramentar algún enfermo reciban buena y caritativamente a los que vinieren a llamarlos y sin dilación alguna lo hagan sea dentro o fuera del pueblo para lo cual tendrán una mula en la caballeriza para no detenerse" (Epístola dirigida a toda la Provincia, 1693, f. 16 v). Los frailes debían además dar ejemplo practicando en ellos mismos este sacramento, ojalá a la vista de los indios: "Ordenamos y mandamos que siempre que hubiere con quién confesarse se confiesen y esto en la iglesia donde le vean los indios para el buen ejemplo y cuando faltare lo busquen en la doctrina más cercana, sin que se separe mucho tiempo. Y si en el pueblo se hallare alguno aprobado por el ordinario, permitimos se confiese con él, aunque sea de fuera de la religión" (Epístola dirigida a toda la Provincia, 1693, f. 14v). Por mandato del maestro general cada dos años se suspendían las licencias de los confesores, hasta tanto no fueran examinados, bien en el convento de Quito o directamente por el provincial o sus visitadores en la visita de las doctrinas y conventos. Por esta razón, vista "la servidumbre del examen", el provincial recomendaba que todos los frailes sacerdotes "procuraran estudiar moral” (Epístola dirigida a toda la Provincia, 1693, f. 13 v).

12 Las lámparas debían estar "encendidas siempre en todos los lugares donde estuviese colocado nuestro señor sacramentado". Cada semana se debían renovar "las especies sacramentales purificando el pixis [copón o cáliz] donde estuvieren colocadas, procurando que los corporales cálices, vinajeras y crismas, estén con toda limpieza y el sagrario delicadamente adornado" (Epístola dirigida a toda la Provincia, 1693, f. 4).

13 Todos los lunes se oficiaba misa cantada y procesión de difuntos a la que estaban obligados todos los frailes, "so pena de un día de pan y agua". Para honrar a los religiosos muertos, en la provincia de Santa Catalina se tenía por costumbre que en cada uno de los conventos, casas y doctrinas se dijeran tres misas si el difunto era sacerdote, tres rosarios si era lego, y tres veces los salmos penitenciales si era un novicio. Por ello, a la muerte de un religioso el prior debía notificar "el fallecimiento a la doctrina o convento más cercano y este al siguiente haciendo lo propio para que de esta suerte no se retarden los sacrificios" (Epístola dirigida a toda la Provincia, 1693, f. 4). Además, el prior debía asentar en una tablilla visible en la sacristía los nombres de los religiosos que muriesen de un capítulo a otro, para recordar "a los sacerdotes encomendarlos a Dios en sus sacrificios”. El 29 de abril. 
En cuanto los estudios, las lecciones de artes y teología eran "indefectibles en todo el año", menos los domingos y las fiestas de precepto, entre otras, los días de Santa Catalina virgen y mártir, "por ser patrona de toda la provincia”, de San Francisco, ${ }^{14}$ de la "traslación del Angélico Doctor" Santo Tomás, ${ }^{15}$ y la semana mayor, contando desde "la dominica de ramos hasta la dominica in albis". ${ }^{16}$ El tiempo de vacaciones era "a saber desde la Magdalena hasta la Santa Cruz", ${ }^{17}$ pero también se daban de asueto "las ferias quintas de todo el año [los jueves] salvo si entre semana hubo algún día de fiesta, que entonces [era] día lectivo" (Epístola dirigida a toda la Provincia, 1693, f. 8). El provincial García fue enfático en ordenar que por mandato del maestro general Antonio de Monroy, ${ }^{18}$ no se debían omitir las lecciones ni en adviento ni en cuaresma, periodos llamados "de recreaciones", pero solo porque los prelados podían dispensar "en el silencio" y permitir "algunos juegos lícitos” (Epístola dirigida a toda la Provincia, 1693, f. 8v).

Todos los días del año, menos los de guardar ayuno, uno de los estudiantes de Teología debía "de las diez a las once defender una cuestión moral, precediendo a ella el maestro de estudiantes resolviendo las dificultades [...], asistiendo toda la comunidad sin excepción de persona alguna para lo cual se hará señal con la campana" (Epistola dirigida a toda la Provincia, 1693, f. 8). Asimismo, "todos los días lectivos desde las tres hasta las cinco [había] conferencia común de artes menos las ferias sextas [los viernes] porque en ellas se ha de defender una cuestión de artes o teología" (Epístola dirigida a toda la Provincia, 1693, f. 8). Por orden de maestro Juan Bautista de Marinis, ${ }^{19}$ ningún religioso podía ser "proveído [del] sagrado orden de presbiterato" sin haber concluido sus estudios, excepto aquel que estando en el último

14 El 4 de octubre.

15 El 28 de enero.

16 Las dos semanas comprendidas entre el Domingo de Ramos y el segundo domingo de Pascua.

17 Desde el 22 de julio hasta el 14 de septiembre.

18 Fraile novohispano que gobernó la Orden de Predicadores entre 1677 y 1686.

19 Maestro general de la Orden entre 1650 y 1669. 
año de sus cursos y "fuese buen estudiante y exemplar en las costumbres”, recibiese licencia del provincial. De todas maneras, también por mandato de Marinis, tampoco podían oponerse a curatos los estudiantes que no hubieran cursado como mínimo nueve años de Teología.

El ramo de la administración también fue reglado con varias disposiciones. Entre otros mandatos, fray Bartolomé pidió cuidado en el registro y manejo de los libros (de bienes, ${ }^{20}$ de cuentas $^{21}$ y de hacienda ${ }^{22}$ ), en la organización del depósito ${ }^{23}$ y en la escrupulosa entrega de cuentas entre los priores salientes y entrantes. Recomendaba especialmente hacer cuentas semanales del gasto y recibo, las cuales debían leerse en

20 "Ordenamos y mandamos a los reverendos padres priores de esta provincia que dentro de seis meses hagan un libro con el título de bienes del convento en el cual pongan todas las alhajas del convento y sacristía como son vasos sagrados, ornamentos, etc. Comenzando con desde el altar mayor, la custodia con las piedras que tuviere (...) santos así de pincel como de escultura, lámparas, mesas, asientos, etc. con individuación de cada celda" (Epístola dirigida a toda la Provincia, 1693, f. 9).

21 "Ordenamos que en los libros de gasto y recibo se pongan las partidas con distinción, individuando el día en que se refiere, de que tercio, en que mes y en qué año, etc., y si son partidas de gasto no se pongan por junto así en las cosas comestibles como en las obras, sino día por día, con individuación de cuantos peones trabajaron aquel día y cuantos alarifes, y su fuere gasto de cosas comestibles, se ponga con distinción el género y precio, aunque sea medio real en distintas líneas, porque de lo contrario se siguen algunos inconvenientes” (Epístola dirigida a toda la Provincia, 1693, f. 9v).

22 “Ordenamos y mandamos que en todas las haciendas y en cada una haya un libro donde se escriba todo el gasto y fruto que se cogieren y sembraren con claridad y distinción de día mes y año, y persona por mano de quién se gastó y recibió. Ordenamos que en dicho libro se escriba el inventario de todos los bienes e instrumentos de la hacienda y casa y se ponga el aumento con día, mes y año y persona que lo hizo, y por él entregue el que sale al que entra y los dos firmen porque de otra suerte no se pasará en cuenta, y lo que faltare del inventario se hará a costa del que entra si lo recibe sin él" (Epístola dirigida a toda la Provincia, 1693, f. 10).

23 Bajo "pena de absolución de oficio", todos los priores debían "con toda brevedad" mandar hacer un arca con tres llaves y en ella se [poner] los libros de grado y cuantos papeles y escrituras del convento en índice de todo y teniendo cada depositario su llave, nunca se abra el depósito sin que estén juntos y en esta arca se guardará el dinero del convento y de los proventos" (Epístola dirigida a toda la Provincia, 1693, f. 9v). 
voz alta los domingos en la noche en presencia del prior, del procurador y los depositarios.

Pero los asuntos que al parecer más preocupaban al provincial eran la disciplina y la predicación entre los naturales. Sobre el régimen disciplinario dejó expresas las sanciones frente a diversas situaciones por las que se consideraba alterada la vida regular. Por ejemplo, pena de absolución de oficio para los priores que permitieran a sus religiosos comer "huevos y lacticinios en las cuaresmas, advientos, vigilias y témporas" por estar "prohibido por derecho canónico a los regulares debajo de pecado mortal" (Epístola dirigida a toda la Provincia, 1693, f. 4). También para aquellos que no siguieran "la secuela de la vida en común”, especialmente la asistencia al refectorio. Pena de excomunión mayor para el que se ausentara del convento so pretexto de medicinarse o curarse de alguna enfermedad. ${ }^{24}$ Tres días de pan y agua al que no fuera moderado en el vestir y usara "profanidades seculares" como "sábanas de lienzo", "capas de resplandor”, “calzones de seda" o "vestidura de grana que vulgarmente llaman armilla o fustacol” (Epístola dirigida a toda la Provincia, 1693, ff. 6-6v). Igual sanción se le aplicaba al que "en público o en secreto [usara] de los términos seculares o de dominio" para dirigirse a un regular, ${ }^{25}$ a los que salían de la conventualidad sin pedir permiso ${ }^{26}$ y a aquellos que usaban "por palabras o por escrito dos o tres apellidos". Finalmente,

24 Al respecto carga las conciencias de los priores para que nunca falten medios para pagar medicinas o médicos, aunque admite que, "como en los pueblos y villas no hay boticas ni médico, sino algunas mujeres de edad que por la práctica y continuación en curar han adquirido algún conocimiento, podrán entrar a la celda del enfermo acompañadas de los padres más antiguos y prior del convento, adonde asistirán hasta que se apliquen las medicinas y terminada la función volverán a salir vía recta acompañadas de dichos padres hasta la portería" (Epístola dirigida a toda la Provincia, 1693, f. 5v).

25 Por ejemplo, "Vuestra Merced, Usted, Señor, Tu, Vos, y otros equivalentes a estos". Pide en cambio que se usaran "Vuestra Piedad, Reverencia o Caridad" (Epístola dirigida a toda la Provincia, 1693, f. 11).

26 En este caso se aplicaba un día de régimen a pan y agua por la primera vez, dos días por la segunda y a los "contumaces" o reincidentes por tercera vez se les enviaba al convento de Quito, donde eran retenidos sin permiso para salir por todo un año (Epístola dirigida a toda la Provincia, 1693, f. 11). 
la "pena de privación de voz activa y pasiva" a los religiosos que fueran a "convento de monjas a hablar en los locutorios, puertas o tornos, sino es que sea con madre, hermana o parienta hasta el cuarto grado y eso con espacial licencia del reverendo padre prior" (Epístola dirigida a toda la Provincia, 1693, f. 12).

La epístola de fray Bartolomé también dejó consagradas infinidad de prohibiciones, entre otras, que se entregara "plata" a los religiosos, ${ }^{27}$ que los novicios tuvieran trato y comunicación con los conventuales, que los priores tuvieran cubicularios o asistentes personales entre los hermanos del noviciado, que entraran mujeres a los conventos, "aunque sea india o mulata, que pase de siete años" (Epistola dirigida a toda la Provincia, 1693, f. 11v), que se jugara "a los naipes, aunque sea por género de recreación”, que se hicieran “celebridades profanas, como son músicas, bailes y farsas jocosas" para conmemorar los años de los prelados, que se brindara a la salud de cualquier persona, que se vieran "agitar toros" 28 o se oyeran "farsas o comedias".

En lo referente a las doctrinas se resalta la importancia de la buena conducta del cura, "advirtiendo que como gente de menos razón se mueven más por ejemplo que por palabras o enseñanza” (Epístola dirigida a toda la Provincia, 1693, f. 14). De todas maneras, el provincial encarecía hacerles "pláticas" a los indios para explicarles la doctrina y los misterios de la fe. ${ }^{29}$ Cada doctrinero debía levantar:

27 Solo se les podía dar "género por lo que da la religión, como son zapatos, jabón, velas y vestuario” (Epístola dirigida a toda la Provincia, 1693, ff. 4v-5).

28 La asistencia a corridas de toros estaba prohibida para los regulares, bajo pecado mortal, por la bula de Pío V De salutis gregis dominici del primero de noviembre de 1567 (San Pío V, 1567).

29 "Como son la inteligividad [sic] y efecto del sacramento de la penitencia, inmortalidad del alma, pena y código eterno, pena temporal del purgatorio, la real presencia de Xpto (Cristo) señor Nuestro Sacrificado en la eucaristía” (Epístola dirigida a toda la Provincia, 1693, f. 14v). Se encarecía especialmente "[instruir] a los más capaces para poder comulgar, así del misterio como de la disposición que se requiere para recibir tan alto sacramento y estando dispuestos provean de lo necesario así para comulgarles como para darles el viático, para lo cual harán un relicario pequeño de plata en que llevar las formas con la decencia posible y este estará siempre dentro del sagrario" (Epístola dirigida a toda la Provincia, 1693, ff. 15-15v). 
...un padrón por los pueblos, escribiendo los nombres de los indios e indias y muchachos, por el cual los llamará todos los días a los pequeños y les dirá doctrina general, y a los grandes les enseñará la doctrina cristiana y las demás oraciones que se deben enseñar (...) más porque se enteren bien les harán rezar por la mañana en lengua castellana, y en la tarde en la del Inga (Epistola dirigida a toda la Provincia, 1693, f. 14v-15). ${ }^{30}$

El doctrinero dominico, al igual que sus hermanos en los conventos, no podía ausentarse sin permiso del superior, y en caso de ser imperiosa su salida por alguna diligencia o contingencia, siempre debía dejar encargado al doctrinero más cercano estar presto a concurrir ante cualquier necesidad. También guardaban clausura, quedándoles terminantemente prohibido que:

Dentre en la casa del padre doctrinero mujer alguna o muchacha en la parte donde habita porque está mandado por el ilustrísimo señor don fray Antonio de Monroy siendo nuestro general del orden se guarde clausura en las doctrinas por o cual procurará que el servicio de cocina y panadería sea por indios y no por mujeres (Epístola dirigida a toda la Provincia, 1693, f. 15v).

Finalmente, como en los conventos debían hacer cuenta de gastos y propinas, de cuyos dineros debían informar al que le sucediese en la tenencia de la doctrina, además de un inventario fijo de especies y aparejos:

30 Sobre la predicación en las lenguas de los naturales agrega: "Ordenamos y estrictísimamente prohibimos el que se nombren curas de indios sin que sepan la lengua general del Inga porque es necesaria saberla para predicarles los santos evangelios y administrarles el pasto espiritual y ser de derecho divino y positivo el que los curas lo sepan y ahora nuevamente mandarlo nuestro reverendo padre maestro general (...) que ni por compañero ni propietario nomínese para curas los que no supieren el idioma y que los que hayan de ser curas sean primero examinados en la lengua, todo lo cual desde ahora y para entonces declaramos por inhábiles para curas a todos los que no supieren la lengua" (Epistola dirigida a toda la Provincia, 1693, f. 16v). 
Ordenamos que cuando sea removido algún cura dejase al sucesor los seis platos, un peso de velas, dos fanegas de trigo, dos borregos, una arroba de sal, cuatro aves con su gallo, una de manteca, dos fanegas de papas, aderentes de cocina que vulgarmente llaman ollas (Epistola dirigida a toda la Provincia, 1693, f. 15v).

\section{La visita regia de 1777 en el convento de Cartagena}

Al momento de efectuarse las visitas mandadas por el rey Carlos III, la desconfianza frente al ambiente que imperaba en los conventos americanos llegaba a tal punto que el mismo maestro general de la Orden de Predicadores, fray Juan Tomás de Boxadors, recomendaba que como garantía de la probidad de los visitadores enviados a Indias, entre cuyas prendas debía sobresalir la fidelidad al rey, se privilegiaran para tal encargo a los españoles que vivieran en España sobre los peninsulares radicados en América. Boxadors, quien nunca cuestionó las pretensiones del Monarca, y antes bien le dio "las más humildes gracias de la paternal solicitud con que se digna procurar la mejora de mis hijos" (AGI, Indiferente, Documento 3041, f. 3v, citado en Plata, 2012, p. 194) se aprestó con diligencia a implementar las visitas. Sin embargo, las inspecciones a los conventos dominicos neogranadinos tuvieron múltiples inconvenientes y retrasos, ocasionados principalmente por la negativa de los frailes designados de trasladarse a América, llegando a excusarse hasta tres de ellos. Finalmente (aunque también trataron de recusar la obligación) fueron enviados los padres fray Sebastián Pier para los conventos del interior de la provincia de San Antonino (incluido el de la capital), fray Lucas Vara para los conventos de la provincia de Quito (la cual comprendía los del sureste del Nuevo Reino de Granada), y fray Ángel Azcoytia para de los conventos de la costa Caribe (Plata, 2012, p. 196).

Así, poco más de siete años después de sancionada la real instrucción para restablecer la disciplina monástica en los "países ultramarinos”, al visitador reformador Azcoytia le correspondió inspeccionar el estado del 
claustro de Cartagena. Según rezaba el mandato real al cuál debían ajustar su proceder los visitadores, Azcoytia tenía que, en su orden, "restablecer la vida común dentro del claustro [...], por dimanar de la falta de clausura la principal relajación” (Carlos III, 1769/1850, p. 169); prohibir sin excepción que los religiosos tuvieran "peculio particular, ni manejo de bienes propios o de sus parientes, porque todo esto es incompatible con el voto de pobreza religiosa y un lamentable desorden"; prescindir de "los comercios, granjerías y otras ocupaciones que distraen a las personas religiosas, [vendiéndolas], arrendándoles o encomendándolas a seglares"; "arreglar" o reducir el número de religiosos "de suerte que [fuera] invariable, teniendo consideración a las rentas del convento, [y] moderando la dotación de hábitos con respecto al número que se [estableciera] como fijo"; y, finalmente, suprimir "los conventillos, que por carecer de número suficiente de religiosos no forman comunidad" (Carlos III, 1769/1850, p. 170).

En orden a contener el supuesto "desafecto con que se [hablaba] contra el gobierno en las Indias" debido a "las malas impresiones" introducidas por "los expulsos" de la Compañía, temor que estaba a la base de la legislación regalista con la cual se promovió la reforma del clero, la instrucción era clara: los visitadores debían poner especial empeño en vigilar todas aquellas doctrinas "que si no se atajan, siempre engendran humores, que a cierto tiempo [hacen] muy mala fermentación" (Carlos III, 1769/1850, p. 168). Por este motivo, el visitador Azcoytia estaba facultado para restablecer los estudios, pero "[deponiendo] opiniones laxas, atendiéndose a las seguras y bien recibidas [...] apartando todo odio y espíritu de escuela en los que deben vivir unidos en paz y caridad cristiana, para hacerse recomendables a los fieles con su mansedumbre evangélica" (Carlos III, 1769/1850, p. 171). Consiguiente a esta "buena enseñanza”, fray Ángel tenía que establecer en los conventos "el buen uso de la oratoria cristiana y predicación, de suerte que los sermones se [redujeran] a la moral cristiana para reprender los vicios, al dogma para enseñar la doctrina, y a la imitación de los santos, depuestas alegorías y comparaciones odiosas que no [estuvieran] fundadas en la verdad". Asimismo, debía esmerarse en que los regulares, "siguiendo la doctrina evangélica y apostólica” y "como máxima fundamental del cristianismo", utilizaran "no solo los 
púlpitos y confesionarios, sino también las conversaciones y discursos familiares", para inspirar en los fieles "el respeto y amor al soberano y la obediencia a los ministros" (Carlos III, 1769/1850, p. 171). En suma, en la visita regia se debía ante todo procurar "desarraigar las murmuraciones y declamaciones con que los regulares expulsos de la Compañía procuraban indisponer los ánimos", no solo como "obligación en conciencia de parte de los religiosos en calidad de sacerdotes", sino porque los regulares, como vasallos de España, habían sido admitidos en "aquellos dilatados dominios" para establecer "la verdadera creencia, con gloria del nombre español y en desempeño del renombre de rey católico" (Carlos III, 1769/1850, p. 172).

A pesar de las amplias facultades y las grandes expectativas, la visita de 1777 no introdujo cambios significativos en la vida regular local, ni en Cartagena ni en las demás ciudades del Nuevo Reino. Apenas una década más tarde, el arzobispo virrey Antonio Caballero y Góngora advertía que "por haberse tenido consideración a causas y circunstancias locales”, podían caer en desuso las medidas tomadas por los visitadores regios para restablecer la vida común en los claustros ("Relación del estado", 1789/1989, p. 385). En efecto, más que reformas efectivas, del paso de Azcoytia por San José solo quedó una agria disputa de sus conventuales con los superiores de la provincia apostados en la capital, por definir a quien le correspondía sufragar los gastos del visitador real.

Quince años después de la visita regia, los dominicos de Cartagena todavía pretendían que se les descontaran de la deuda acumulada a la provincia en los últimos años por concepto de tributos (como el de “derrama”), 670 pesos, 2 reales y 1 cuartillo por la manutención y el hospedaje del padre visitador Azcoytia, ${ }^{31}$ quien gravemente enfermo,

31 Para 1792 los conventuales de Cartagena tenían acumulada una deuda de 1.250 pesos repartidos así: 1.050 pesos correspondientes a las contribuciones comprendidas entre los tercios de navidad de 1786 a 1791 (“cinco años cabales" a razón de 210 pesos cada uno); 80 pesos de la derrama del capítulo provincial celebrado en 1789; y 120 pesos de las obligaciones o impuestos abonados por el convento de Riohacha a la Provincia, los cuales se entregaron - como estaba estipulado- en el claustro de San José, pero que este último de manera irregular nunca se los entregó las autoridades provinciales en Santafé (véase 
nunca regresó a España y murió en Cartagena en 1780 (Alzate, Benavides y Escobar, 2014) lo cual quizá explica la reticencia de los visitadores de viajar a Indias. ${ }^{32}$

La aparente intrascendencia de la visita de 1777 se comprende mejor si se toma en cuenta que en los años siguientes, en pos de la defensa de la ciudad, el convento tuvo que someterse a la socorrida práctica de convertirlo en cuartel militar, y albergar en sus celdas a otros tres regimientos: el de la Corona entre 1782 y 1784, el de la Princesa entre 1785 y 1789, y el Fijo de la plaza entre 1793 y 1794 (Vidal, 2007, p. 115).

\section{Cierre}

Para finales del siglo XVIII al parecer seguía vigente la criticada relajación de costumbres entre los religiosos neogranadinos, pues el virrey José de Ezpeleta denunciaba "los gravísimos inconvenientes que resultan de mantenerse los regulares por algún tiempo fuera del claustro", lo cual según decía, sucedía frecuentemente "a pretexto del servicio de curatos" ("Relación del gobierno", 1796/1989, p. 173). A su juicio, aún si se redujera de nuevo a sus conventualidades a los regulares

Deuda del convento de Cartagena, 1792, f. 8r). La pretensión de descontar de esta deuda el hospedaje del padre Azcoytia, fue repudiada por el padre colector, fray Manuel León, enviado a Cartagena con facultades de visitador con el expreso mandato de no regresar a Santafé hasta que no se saldara el atraso. En consideración de fray Manuel, de darle aprobación a ese descuento el convento de Santafé tendría el mismo derecho, pues allí se alojaron dos padres visitadores por ese mismo periodo (los padres Pier y Vara). Además, argumentó que aún sin la dignidad de visitador, bastaba el carácter de religioso para que el convento lo hubiera asistido, máxime cuando dicho padre "echó derrama de 117 pesos” en el convento, los cuales nunca pasaron a la provincia (véase León, 1792, f. 8).

32 No menos peligrosa fue la experiencia de fray Lucas Vara, visitador reformador de los dominicos en Quito, quien perdió la mano derecha por una bala de cañón, cuando la nave que lo conducía de regreso a España fue asediada por una fragata inglesa. Llevado como prisionero a Jamaica, según le relató al Rey, padeció "cuatro meses toda suerte de martirios y trabajos" (AGI, Indiferente general, 3042, f. 1-2. citado en Plata, 2012, p. 198). 
"prófugos", una vez perdido "el vigor de la disciplina, [olvidado] su instituto y [contraídos] cierta especie de resabios ajenos de su carácter y nada conformes con la regularidad [...], no es de extrañar que desacomodándoles la sujeción y el vigor de la regla sirvan de disgusto a los prelados y de mal ejemplo a sus compañeros" ("Relación del gobierno”, 1796/1989, p. 174). Tal situación, decía el gobernante, era "la verdadera y más deplorable enfermedad de los claustros", a cuya solución debían concurrir las jurisdicciones eclesiástica y secular.

Este ambiente siguió imperando hasta mucho después de las guerras de Independencia, dando pie a las nuevas autoridades republicanas para fraguar un plan de supresión de los conventos que no albergaran a por lo menos ocho religiosos. ${ }^{33}$ Innegablemente, las autoridades republicanas heredaron de las peninsulares el interés de "aligerar ciertas cargas" y "corregir la disciplina monástica” — como rezaba la ley de supresión de conventos menores-, circunstancia favorecida por la conversión de muchos conventuales en párrocos.

Así, ni la copiosa legislación interna y externa para arreglar la disciplina, ni el creciente clamor de las autoridades civiles y eclesiásticas para reformar a los regulares, pudieron evitar que, rotos los lazos que los unían a su conventualidad, algunos de los hijos de Santo Domingo marcharan por la senda de la secularización, o sus edificios y rentas fueran destinados a la nueva causa de la educación pública. De esta manera, fueron suprimidos varios de los claustros de los padres predicadores, entre otros, los de Cartagena, Popayán, Santa Marta,

33 La ley del patronato eclesiástico (28 de julio de 1824) sancionó que era potestad del Congreso de la República "permitir o no la fundación de nuevos monasterios y hospitales; suprimir los existentes si lo [considerara] útil, conveniente y oportuno, y dar destino a sus rentas, etc.” (véase Posada, 1865). En el marco de estas facultades, en abril de 1826 el Congreso ordenó dar ejecución a la ley de supresión de conventos menores, sancionada desde el 21 de julio del "año II" (1821). La medida buscaba "procurar la conservación de la disciplina monástica y el fomento de la instrucción pública”, declarando suspendidos todos los conventos "que no tuvieren ocho religiosos sacerdotes de continua y permanente residencia dentro de sus claustros" (Ley de supresión de conventos menores, 1826, 1-2). 
Pamplona y Cali, poniendo punto final a una obra que hasta entonces había acompañado la suerte de estas ciudades.

\section{Referencias}

\section{Fuentes primarias}

Deuda del convento de Cartagena con la Provincia. (1792). Fondo San Antonino, Sección Conventos, Cartagena, (Caja 1, f. 8r). Bogotá, Archivo de la Provincia Dominicana de Colombia.

Epístola dirigida a toda la Provincia de Santa Catalina Virgen y Mártir de Quito por su Provincial, fray Bartolomé García, Quito. (30 de mayo de 1693). Colonia, Eclesiástico, Órdenes Sagradas, Asuntos varios. (Sig.: 9546 (Col. E I -16 or). ff. 1-17). Popayán, Archivo Central del Cauca.

Léon, M. O.P. (1792). Carta de fray Manuel de León al padre Prior informándole sobre algunos gastos y deudas. Fondo San Antonino, Sección Conventos, Cartagena (Caja 2, Carpeta 1, f. 8). Bogotá, Archivo de la Provincia Dominicana de Colombia.

\section{Fuentes impresas}

Carlos III. (16 de octubre de 1769/1850). Real Instrucción sobre restablecer la disciplina monástica. San Lorenzo del Escorial. En J. Eyzaguirre, Historia eclesiástica, política y literaria de Chile (Tomo I, documento No. 29 (El rei), pp. 167-176) Valparaíso: Imprenta del Comercio.

Estado del Virreinato de Santafé, Nuevo Reino de Granada, por el Dr. D. Francisco Antonio Moreno y Escandón. (1772/1989). En G. Colmenares, Relaciones e informes de los gobernantes de Nueva Granada (Tomo I, Prólogo, Sección V, pp. 153-270). Bogotá: Fondo de Promoción de la Cultura del Banco Popular.

Instrucción que deja a su sucesor en el mando el Virrey D. Manuel Gurior. (1776/1989). En G. Colmenares, Relaciones e informes de los gobernantes de Nueva Granada (Tomo I, Prólogo, Sección VI, pp. 271-359). Bogotá: Fondo de Promoción de la Cultura del Banco Popular. 
Ley sobre supresión de conventos menores del 7 de abril de 1826. (16 de abril de 1826). Gaceta de Colombia, 235. Recuperado de http://www. banrepcultural. org/sites/default/files/revista/blabr1142013_n_235.pdf

López, I. (1787). El sacrosanto y ecuménico concilio de Trento. Madrid: la Imprenta Real.

Regla de Nuestro Padre San Agustín y Constituciones de la Sagrada Orden de Predicadores, con algunas de sus glosas, explicación de sus votos y práctica de la Oración para el uso de sus religiosos legos (1787). Barcelona: Bernardo Pla (Impresor).

Relación del estado del Virreinato de Santafé, que hace el Excmo. Sr. D. Pedro Messía de la Zerda a su sucesor el Excmo. Sr. D. Manuel Guirior. (1772/1989). En G. Colmenares, Relaciones e informes de los gobernantes de Nueva Granada (Tomos 1, Prólogo, Sección IV, pp. 123-152). Bogotá: Fondo de Promoción de la Cultura del Banco Popular.

Relación del gobierno del Exmo. Sor. Dn. Josed de Ezpeleta, etc. (1796/1989). En G. Colmenares, Relaciones e informes de los gobernantes de Nueva Granada (Tomos II, pp. 153-311). Bogotá: Fondo de Promoción de la Cultura del Banco Popular.

Relación del estado del Nuevo Reino de Granada, que hace el Arzobispo Obispo de Córdoba a su sucesor el Excmo. Sr. D. Francisco Gil y Lemos. (1789/1989). En G. Colmenares, Relaciones e informes de los gobernantes de Nueva Granada (Tomo I, pp. 361-492). Bogotá: Fondo de Promoción de la Cultura del Banco Popular.

Romanis, H. (1546). Doctrina de religiosos, compuesta por el religioso fray Humberto de Romanis, quinto maestro general de la Orden de los Predicadores. En la que se hallará ingeniosamente sacado y recogido lo mejor de todo lo bueno que en las otras instrucciones de religiosos se contiene. Salamanca: Juan de Junta (impresor).

San Pío V. (1567). Bula “De Salutis Regis Rominici”. Recuperado de http:// www. eroj.org/paginas/piov.htm

\section{Fuentes secundarias}

Arranz, A. (2003). Las visitas pastorales a las parroquias de la Corona de Castilla durante la Baja Edad Media. En la España Medieval, 26, 295-339. 
Alzate, C.; Benavides, F. y Escobar, M. (2014). Vida cotidiana en el Convento Universidad San José en Cartagena de Indias hacia mediados del siglo XVIII y comienzos del XIX. Bogotá: Instituto de Estudios Socio-Históricos Fray Alonso de Zamora -Ieshfaz-, Universidad Santo Tomás. Las visitas pastorales a las parroquias de la Corona de Castilla durante la Baja Edad Media. En la España Medieval, 26, 295-339.

Barrio, M. (2000). Reforma y supresión de los regulares en España al final del antiguo régimen. Investigaciones Históricas. Época Moderna y Contemporánea, 20, 89-118.

Cortés, A. (1989). La política religiosa de Carlos III y las órdenes mendicantes. Granada: Universidad de Granada.

Domínguez, A. (1986). Economía y sociedad en América española durante el reinado de Carlos III. En Archivo General de Indias (ed.) La América española en la época de Carlos III (pp. 31-37). Sevilla: Ministerio de Cultura.

Esponera, A. (2013). La vida cotidiana conventual a fines del siglo XVIII en cinco provincias de la América Hispana de la Orden de Predicadores. En Hispania Sacra, LXV, 315-358.

Martí, F. (2004). Carlos III y la política religiosa. Madrid: Ediciones Rialp.

Plata, W. (2012). Vida y muerte de un convento. Dominicos y sociedad en Santafé de Bogotá (Colombia), siglos XVI-XIX. Salamanca: Editorial San Esteban.

Posada, J. (1865). Memorias histórico-politicas. Bogotá: Imprenta de Foción Mantilla. Recuperado de http://www.banrepcultural.org/blaavirtual/historia/ memhist/mem45.htm.

Sánchez-Blanco, F. (2002). El absolutismo y las luces en el reinado de Carlos III. Madrid: Marcial Pons Ediciones de Historia.

Sarrailh, J. (1957). La España ilustrada de la segunda mitad del siglo XVIII. México: Fondo de Cultura Económica.

Serrano, E. (2014). Toledo y los dominicos en la época medieval. Instituciones, economía y sociedad. Cuenca: Ediciones de la Universidad de Castilla-La Mancha.

Vidal, A. (2007). El Convento San José, huella dominica en el periodo colonial. En A. Meisel y H. Calvo (Eds.), Cartagena de Indias en el siglo XVII (pp. 73-120). Cartagena: Banco de la República. 
